\title{
NMR kinetic investigations of the photochemical and thermal reactions of a photochromic chromene
}

\author{
Stéphanie Delbaere*, Jean-Claude Micheau ${ }^{\S}$, Gaston Vermeersch \\ Laboratoire de Physique et LARMN, UMR CNRS 8009, Faculté de Pharmacie, Université de Lille 2, F-59006 Lille, France. \\ $\S$ Laboratoire IMRCP, UMR CNRS 5623, Université Paul Sabatier, F-31062 Toulouse, France \\ sdelbaer@pharma.univ-lille2.fr
}

\section{$\underline{\text { Table of contents }}$}

Characteristic of used filters

UV spectrum of FC in acetonitrile

${ }^{1}$ H NMR Spectrum

${ }^{19}$ F NMR Spectra

Details about the fitting procedure
S2

S2

S3

S4

S5 


\section{Characteristic of used filters}

\begin{tabular}{|c|c|c|c|}
\hline $\begin{array}{r}\text { Schott 011FG09 } \\
\text { Pass-band filter }\end{array}$ & $259<\lambda<388 \mathrm{~nm}$ & $\begin{array}{l}\text { Maximum transmission } \\
\lambda_{\max }=330 \mathrm{~nm}, \mathrm{~T}=71 \%\end{array}$ & $\begin{array}{l}\text { Half-width at 50\% T }(=\mathbf{3 5 . 5 \%}) \\
\lambda=284 \text { and } 371 \mathrm{~nm}(\Delta \lambda=87 \mathrm{~nm})\end{array}$ \\
\hline Oriel 3-74 & & Maximum transmission & Wavelength at $50 \% \mathrm{~T}(=41.5 \%)$ \\
\hline High-pass filter & $\lambda>400 \mathrm{~nm}$ & $\mathrm{~T}=87 \%$ & $\lambda=407 \mathrm{~nm}$ \\
\hline
\end{tabular}

\section{UV spectrum of FC in acetonitrile}

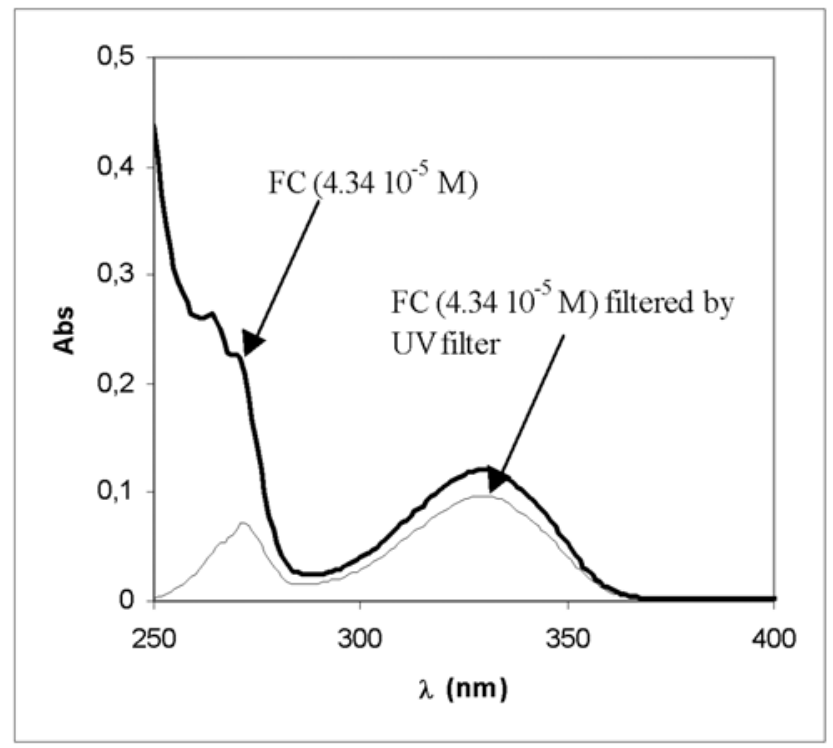

Rem.: Taking into account the emission spectrum of the Xe-Hg lamp makes the low-wavelength action band negligible. 


\section{${ }^{1}$ H NMR Spectrum}

The ${ }^{1} \mathrm{H}$ NMR spectra were recorded, in parallel with the ${ }^{19} \mathrm{~F}$ spectra. These spectra were not integrated because of overlapping signals, making it difficult to obtain accurate values. The characterization of compounds (Chart 1S) is reported in Figure 1S.

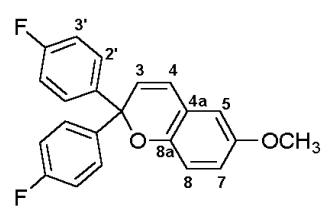

FC

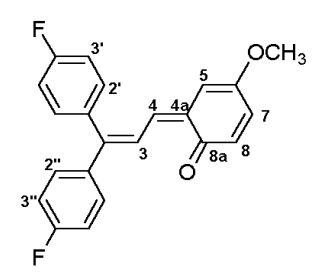

TC

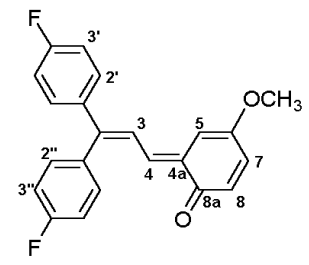

TT

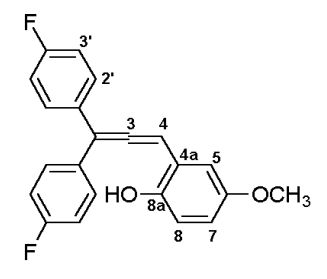

AP

Chart 1S. Structure and numbering of FC, AP, TC and TT.

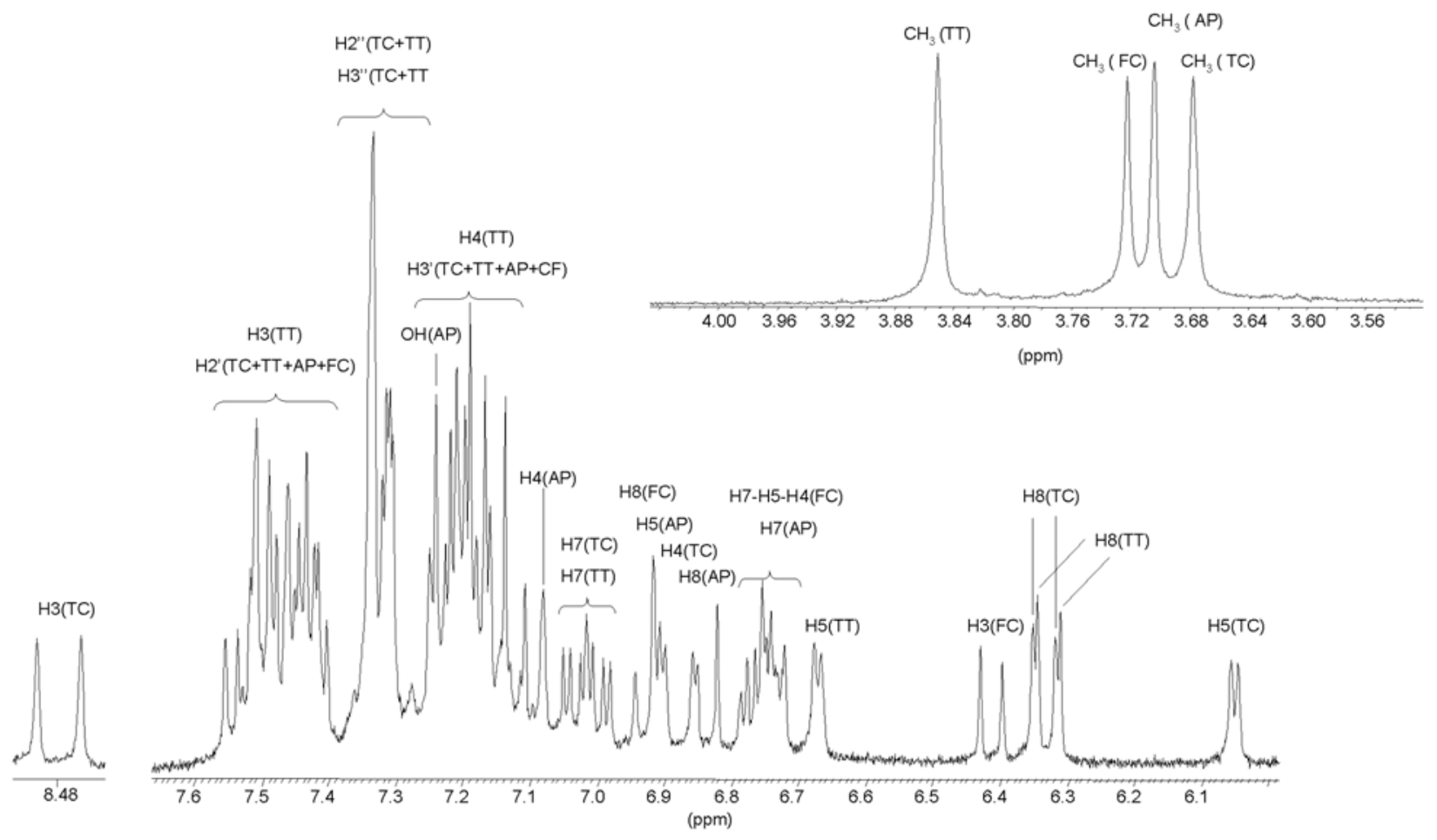

Figure 1S. ${ }^{1} \mathrm{H}$ NMR spectrum with assignment of resonance lines. 


\section{${ }^{19}$ F NMR Spectra}

In Figure 2S, the NMR spectra of the irradiated system just after irradiation and after a long period in the dark (at 264.2K) are reported. The major detected degradation product identified as 4,4-difluoro-benzophenone, presents no time-evolution and is less than $2 \cdot 10^{-4} \mathrm{M}$.

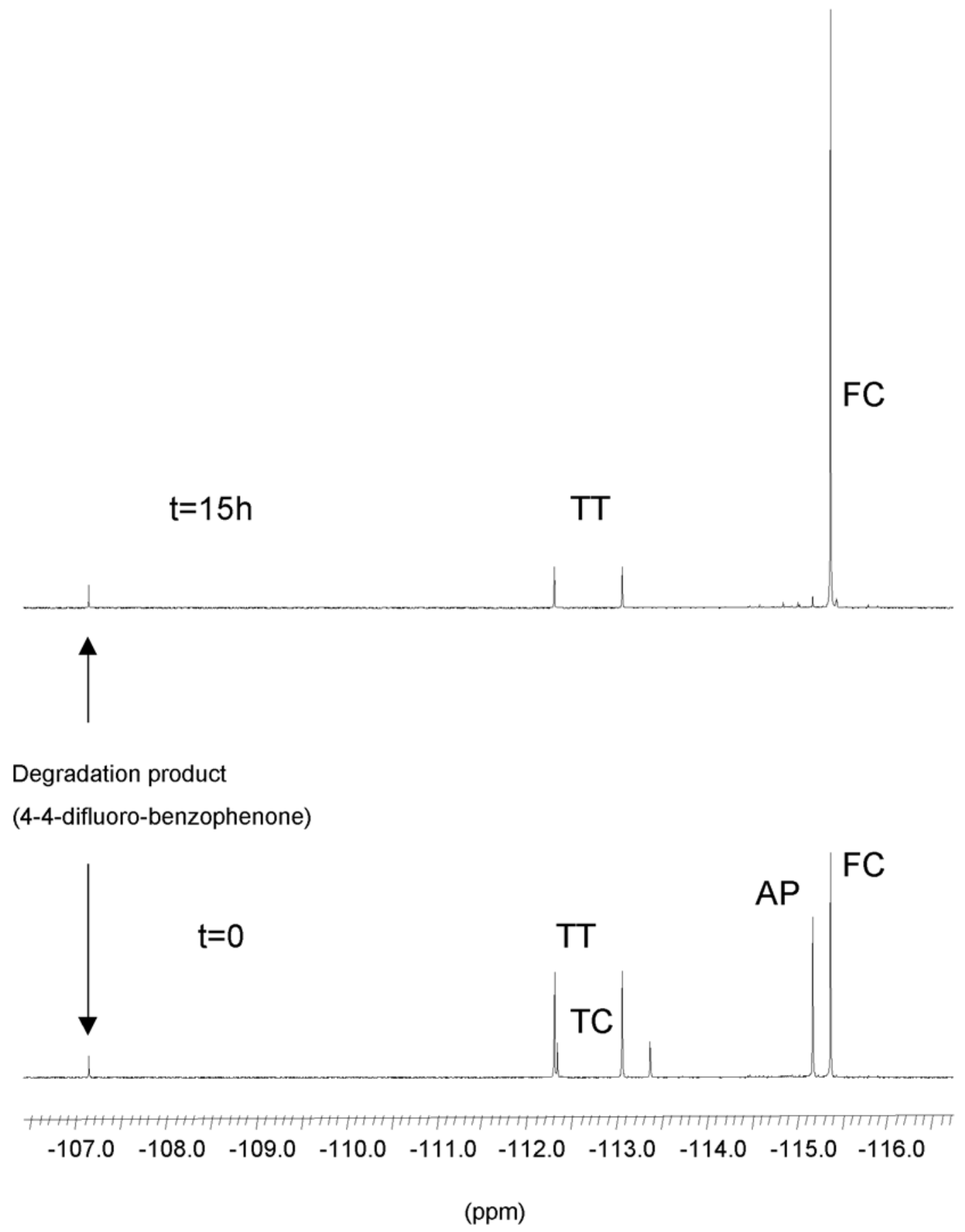

Figure 2S. ${ }^{19} \mathrm{~F}$ NMR spectra at time $=0$ and time $=15 \mathrm{~h}$ of the thermal relaxation process followed at $264.2 \mathrm{~K}$ 


\section{Details about the fitting procedure}

From the general scheme 1S,

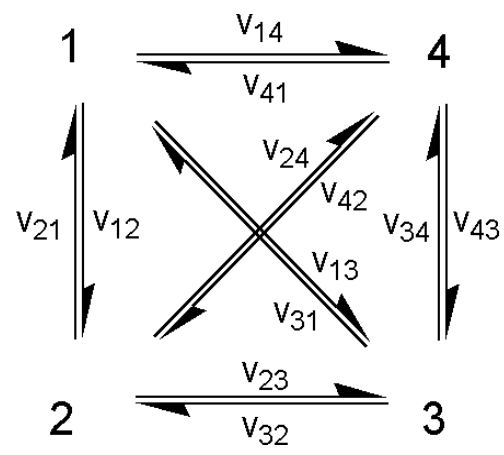

Scheme 1S.

the kinetic equations were deduced :

$$
\begin{aligned}
& \mathrm{d}[\mathbf{1}] / \mathrm{dt}=-\left(\mathrm{v}_{12}+\mathrm{v}_{13}+\mathrm{v}_{14}\right)+\mathrm{v}_{21}+\mathrm{v}_{31}+\mathrm{v}_{41} \\
& \mathrm{~d}[\mathbf{2}] / \mathrm{dt}=-\left(\mathrm{v}_{23}+\mathrm{v}_{24}+\mathrm{v}_{21}\right)+\mathrm{v}_{32}+\mathrm{v}_{42}+\mathrm{v}_{12} \\
& \mathrm{~d}[\mathbf{3}] / \mathrm{dt}=-\left(\mathrm{v}_{34}+\mathrm{v}_{31}+\mathrm{v}_{32}\right)+\mathrm{v}_{43}+\mathrm{v}_{13}+\mathrm{v}_{23} \\
& \mathrm{~d}[\mathbf{4}] / \mathrm{dt}=-\left(\mathrm{v}_{41}+\mathrm{v}_{42}+\mathrm{v}_{43}\right)+\mathrm{v}_{14}+\mathrm{v}_{24}+\mathrm{v}_{34}
\end{aligned}
$$

a mass-balance equation also exists : $[\mathbf{1}]+[\mathbf{2}]+[\mathbf{3}]+[\mathbf{4}]=$ constant

where the concentrations are expressed in mol. $\mathrm{L}^{-1}$ and $\mathrm{v}_{\mathrm{ij}}$, the rate in $\mathrm{mol} \cdot \mathrm{L}^{-1} \cdot \mathrm{s}^{-1}$.

$\mathrm{v}_{\mathrm{ij}}=\Phi_{\mathrm{ij}} \cdot \varepsilon_{\mathrm{i}} \cdot 1 . \mathrm{I}_{0} \cdot \mathrm{F} \cdot\left[\mathrm{X}_{\mathrm{i}}\right]$ for photoinduced processes and $\mathrm{v}_{\mathrm{ij}}=\mathrm{k}_{\mathrm{ij}} \cdot\left[\mathrm{X}_{\mathrm{i}}\right]$ for thermal processes, where $\mathrm{X}_{\mathrm{i}}=\mathbf{1}, \mathbf{2}, \mathbf{3}$ or $\mathbf{4}$.

\section{General procedure}

From the general scheme 1S, twelve pathways are possible. All the values are taken into account to start a fitting procedure. Starting values were chosen around $10^{-3}$, and were then refined by trial and error until a good fit was obtained. Finally, the parameters were fitted automatically using an iterative algorithm of the Powell type, designed to minimize the residual quadratic error $\chi^{2}=\Sigma_{\mathrm{n}} \Sigma_{\mathrm{m}}\left(\mathrm{Y}_{\mathrm{cal}}-\mathrm{Y}_{\mathrm{obs}}\right)^{2}$ between the experimental and the calculated curves ( $\mathrm{n}$ is the number of experimental data points and $\mathrm{m}$ the number of kinetic curves). Too-small non-significant parameters were removed one by one until a systematic distancing from the experimental data points was observed. 


\section{UV irradiation kinetics}

From the twelve possible processes, simulations showed that processes $\mathrm{v}_{12}, \mathrm{v}_{13}, \mathrm{v}_{14}, \mathrm{v}_{21}, \mathrm{v}_{23}, \mathrm{v}_{24}$ and $\mathrm{v}_{42}$ were necessary to obtain a good fit. Nothing is really improved if more parameters are added (for instance $\mathrm{v}_{31}, \mathrm{v}_{32}, \mathrm{v}_{34}, \mathrm{v}_{41}, \mathrm{v}_{43}$ ). However, removing only one of these rates, (i.e. by zeroing it) hinders good fitting. To illustrate the approach, two examples are reported:

- $\quad$ Figure 3S illustrates the need for the TC $\rightarrow$ FC path $\left(\mathrm{v}_{21}\right)$

- $\quad$ Figure $4 \mathrm{~S}$ illustrates the need for the $\mathrm{FC} \rightarrow \mathrm{TT}$ and $\mathrm{FC} \rightarrow$ AP paths $\left(\mathrm{v}_{13}\right.$ and $\left.\mathrm{v}_{14}\right)$.

In each figure, signs are experimental concentrations, solid lines are best fits and dashed lines are curves resulting from the suppression of the required parameters.

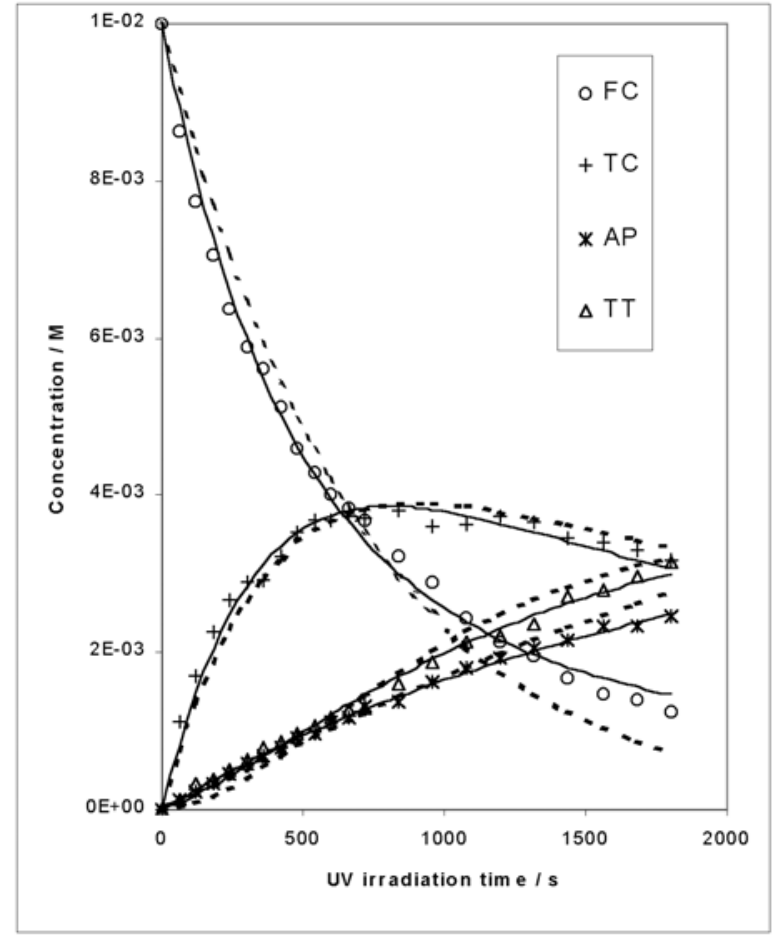

Figure 3S. Solid lines (best fit); dashed lines: tentative fitting without taking into account the $\mathrm{TC} \rightarrow \mathrm{FC}\left(\mathrm{v}_{21}\right)$ process. Signs are experimental concentrations.

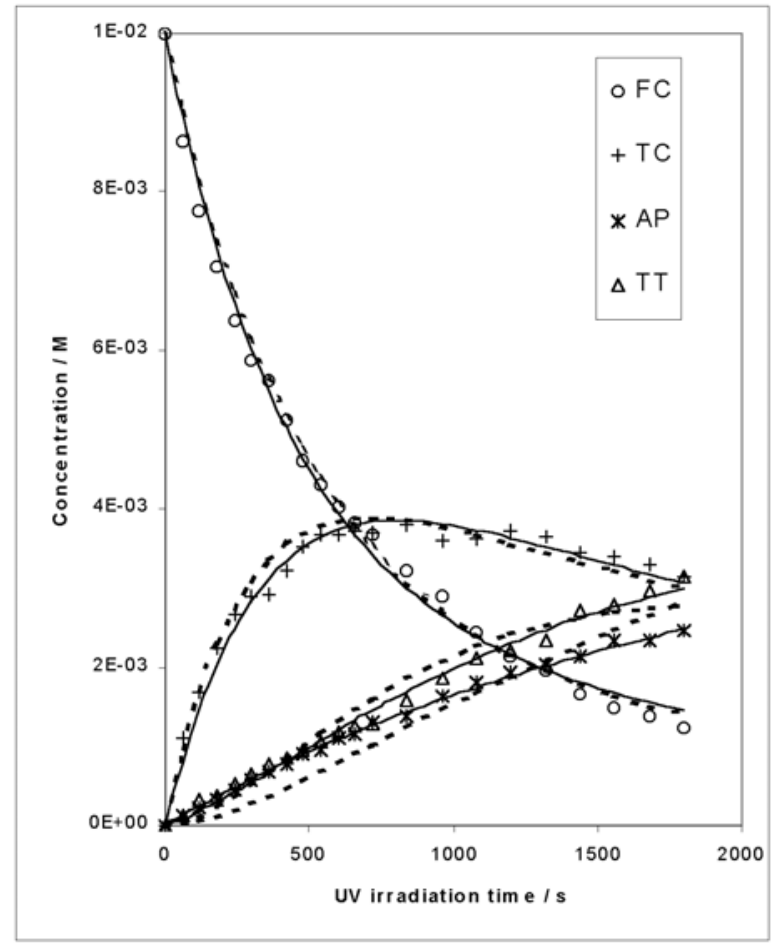

Figure 4S. Solid lines (best fit); dashed lines: tentative fitting without taking into account the $\mathrm{FC} \rightarrow \mathrm{AP}\left(\mathrm{v}_{13}\right)$ and $\mathrm{FC} \rightarrow \mathrm{TT}\left(\mathrm{v}_{14}\right)$ processes. Signs are experimental concentrations. 


\section{Visible irradiation kinetics}

Under irradiation with visible light, only the two merocyanines TC and TT absorb light. It was assumed and checked that: $\mathrm{v}_{12}=\mathrm{v}_{13}=\mathrm{v}_{14}=\mathrm{v}_{31}=\mathrm{v}_{32}=\mathrm{v}_{34}=0$. Within the six remaining parameters, $\mathrm{v}_{21}, \mathrm{v}_{23}, \mathrm{v}_{24}, \mathrm{v}_{41}, \mathrm{v}_{42}$ and $\mathrm{v}_{43}$, it was shown that $\mathrm{v}_{21}, \mathrm{v}_{23}$, and $\mathrm{v}_{42}$ were significant while $\mathrm{v}_{24}, \mathrm{v}_{41}$ and $\mathrm{v}_{43}$ were negligible being more than two orders of magnitude less. The final fitting was not affected by considering only three parameters. However, an important point was to take into account the variation in the photokinetic factor by adding a fourth parameter related to the apparent molar extinction coefficient of TC and TT. Figure $5 \mathrm{~S}$ shows this effect.

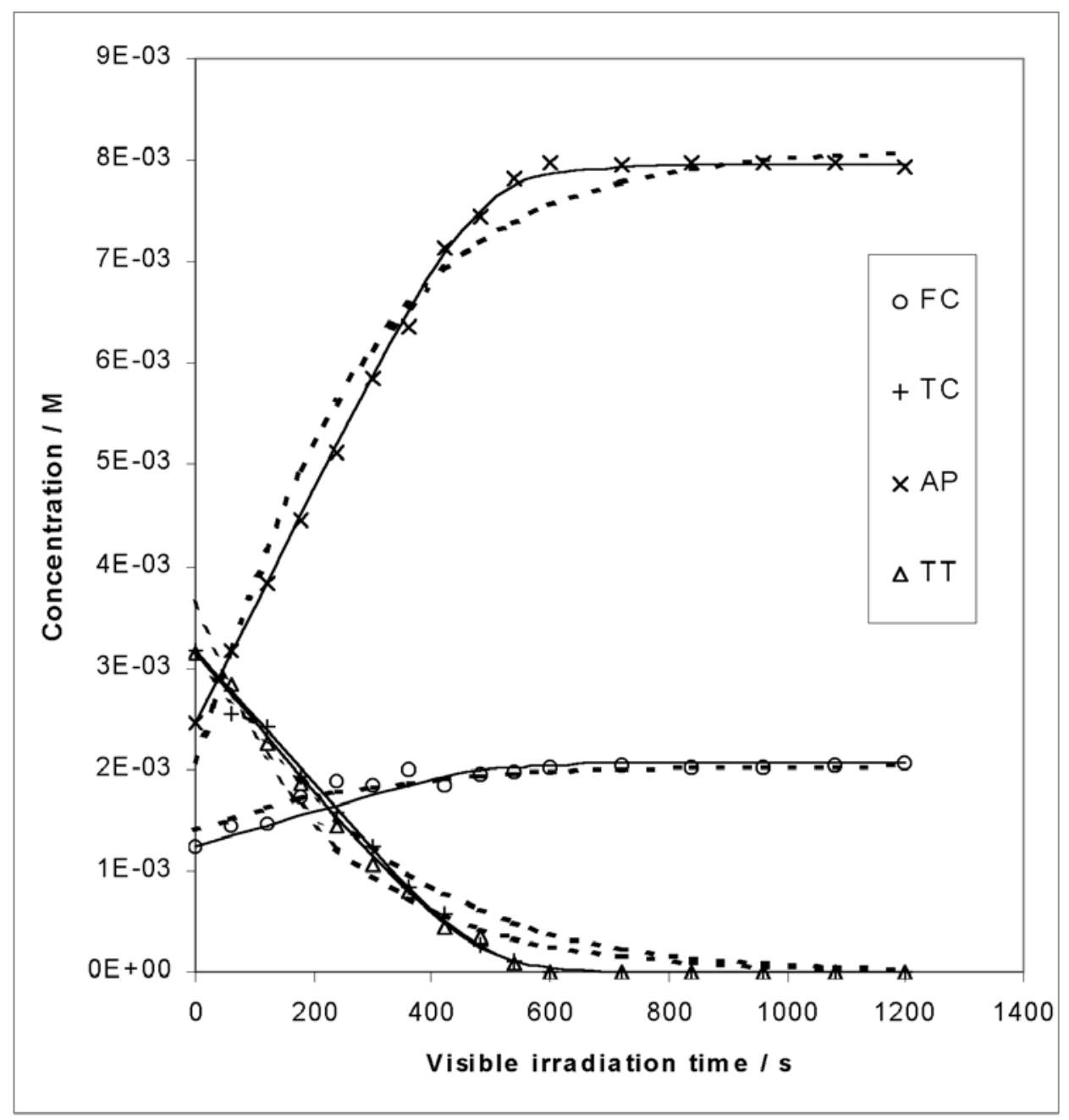

Figure 5S. Analysis of the photokinetic factor effect: Solid lines: best fits assuming that $\mathrm{F}$ varies with an apparent $\varepsilon_{(\mathrm{TT} \text { or TT) }}^{\prime}=$ 528L. $\mathrm{mol}^{-1}$. Dashed lines: tentative fit assuming that $\mathrm{F}$ is constant. Signs are experimental concentrations. 


\section{Thermal data processing}

The same procedure was applied to the whole set of experimental data measured for different temperatures. We started by setting the twelve parameters $\mathrm{v}_{12}, \mathrm{v}_{13}, \mathrm{v}_{14}, \mathrm{v}_{21}, \mathrm{v}_{23}, \mathrm{v}_{24}, \mathrm{v}_{31}, \mathrm{v}_{32}, \mathrm{v}_{34}, \mathrm{v}_{41}, \mathrm{v}_{42}, \mathrm{v}_{43}$ to $\approx 10^{-4}$. After several refinement steps, it appeared that $\mathrm{v}_{12}, \mathrm{v}_{13}, \mathrm{v}_{14}, \mathrm{v}_{23}, \mathrm{v}_{31}, \mathrm{v}_{34}, \mathrm{v}_{41}$ and $\mathrm{v}_{43}$ could be discarded without any loss of fitting quality. To estimate their validity, each of the rate constants deduced was tested to verify Eyring's equation:

$$
\operatorname{Ln}\left(\frac{\mathrm{k}_{\mathrm{ii}}}{\mathrm{T}}\right)=\operatorname{Ln}\left(\frac{\mathrm{k}_{\mathrm{B}}}{\mathrm{h}}\right)+\frac{\Delta \mathrm{S}^{\#}}{\mathrm{R}}-\frac{\Delta \mathrm{H}^{\#}}{\mathrm{RT}}
$$

Results are gathered in Table 1S.

\begin{tabular}{c|c|c|c}
\hline Processes & $\begin{array}{c}\text { Number of experiments } \\
\text { where the process is } \\
\text { detected }\end{array}$ & $\begin{array}{c}\text { Determination coefficients } \\
\mathrm{R}^{2}\end{array}$ & significance \\
\hline $\mathrm{TC} \rightarrow \mathrm{FC}\left(\mathrm{v}_{21}\right)$ & 10 & $98,96 \%$ & $>99 \%$ \\
$\mathrm{TC} \rightarrow \mathrm{TT}\left(\mathrm{v}_{24}\right)$ & 10 & $97,52 \%$ & $>99 \%$ \\
$\mathrm{AP} \rightarrow \mathrm{TC}\left(\mathrm{v}_{32}\right)$ & 10 & $99,66 \%$ & $>99 \%$ \\
$\mathrm{TT} \rightarrow \mathrm{TC}\left(\mathrm{v}_{42}\right)$ & $8^{*}$ & $91,95 \%$ & $>99 \%$
\end{tabular}

Table 1S: Eyring analysis from variable temperature data. All the selected processes give rise to good linearity of the Eyring plots. Note that the TT $\rightarrow$ TC process was not detected at the lowest temperatures $(\mathrm{T}=235$ and $242.77 \mathrm{~K})$.

Table $2 \mathrm{~S}$ reports all the calculated rate constants together with the residual error of each fit $\left(\chi^{2}\right)$ :

\begin{tabular}{ccccc|c}
\hline & $\mathrm{TC} \rightarrow \mathrm{FC}$ & $\mathrm{TC} \rightarrow \mathrm{TT}$ & $\mathrm{AP} \rightarrow \mathrm{TC}$ & $\mathrm{TT} \rightarrow \mathrm{TC}$ & $\chi^{2}$ \\
$\mathrm{~T}(\mathrm{~K})$ & $\mathrm{v}_{21}$ & $\mathrm{v}_{24}$ & $\mathrm{v}_{32}$ & $\mathrm{v}_{42}$ & \\
\hline 235,00 & $2,99 \mathrm{E}-05$ & $1,51 \mathrm{E}-05$ & $1,55 \mathrm{E}-06$ & n.d. & $7,1 \mathrm{E}-10$ \\
242,77 & $1,33 \mathrm{E}-04$ & $5,04 \mathrm{E}-05$ & $3,73 \mathrm{E}-06$ & n.d. & $7,1 \mathrm{E}-10$ \\
244,79 & $2,58 \mathrm{E}-04$ & $7,50 \mathrm{E}-05$ & $5,25 \mathrm{E}-06$ & $4,15 \mathrm{E}-06$ & $5,1 \mathrm{E}-09$ \\
248,91 & $3,23 \mathrm{E}-04$ & $1,20 \mathrm{E}-04$ & $7,95 \mathrm{E}-06$ & $7,62 \mathrm{E}-06$ & $2,8 \mathrm{E}-10$ \\
253,19 & $6,00 \mathrm{E}-04$ & $2,77 \mathrm{E}-04$ & $1,29 \mathrm{E}-05$ & $1,88 \mathrm{E}-05$ & $1,4 \mathrm{E}-09$ \\
254,26 & $8,00 \mathrm{E}-04$ & $5,59 \mathrm{E}-04$ & $1,47 \mathrm{E}-05$ & $3,27 \mathrm{E}-05$ & $1,7 \mathrm{E}-09$ \\
259,35 & $2,14 \mathrm{E}-03-$ & $7,49 \mathrm{E}-04$ & $2,60 \mathrm{E}-05$ & $3,04 \mathrm{E}-05$ & $3,8 \mathrm{E}-09$ \\
260,42 & $2,38 \mathrm{E}-03$ & $8,15 \mathrm{E}-04$ & $2,88 \mathrm{E}-05$ & $4,12 \mathrm{E}-05$ & $1,0 \mathrm{E}-09$ \\
261,74 & $2,42 \mathrm{E}-03$ & $1,06 \mathrm{E}-03$ & $3,32 \mathrm{E}-05$ & $4,74 \mathrm{E}-05$ & $2,6 \mathrm{E}-09$ \\
264,17 & $3,95 \mathrm{E}-03$ & $2,80 \mathrm{E}-03$ & $5,11 \mathrm{E}-05$ & $5,64 \mathrm{E}-05$ & $4,2 \mathrm{E}-09$
\end{tabular}

Table 2S: Calculated rate constants of the selected process and $\chi^{2}$ values of the fittings.

(n.d. indicates that a non-significant value was calculated) 